\title{
Housing / Urban Development Integrated with Flood-Control Reservoirs in Japan
}

\author{
Naoyuki Watanabe ${ }^{1}$ \\ (Received June 2, 2014 / Revised July 25, 2014 / Accepted July 28, 2014)
}

\begin{abstract}
The purpose of this paper is to introduce two integrated urban development projects in Japan that take full advantage of flood-control reservoirs: the Tetsugakudo Park Collective Housing Development Project and the Koshigaya Lake Town Project. The former project implemented cooperatively by the Tokyo metropolitan government in charge of river management, Shinjuku and Nakano wards (in Tokyo) responsible for park management, and the Urban Renaissance Agency, a housing project developer - set a significant precedent for threedimensional river use by realizing the three-dimensional integrated development of a flood control reservoir, a park, and collective housing. The Koshigaya Lake Town Project, launched as a drastic storm water management measure for a low-lying area often plagued by flooding, has achieved a sustainable coexistence between the waterfront environment and the urban living environment, with an artificial flood-control reservoir as the core for urban development. This project is fully committed to environmental coexistence through the optimal use of local environmental resources, with the cooperation of the central government, Saitama Prefecture and Koshigaya City.
\end{abstract}

Key words: Flood-control Reservoir, Housing Development, Urban Development, Three-dimensional Use, Environmental Coexistence

\section{Introduction}

Rapid urbanization and urban sprawl have often considerably diminished the capacity for ground-water retention compared to before land use conversion into urbanized areas, thereby causing an increased outflow of storm water onto the ground surface. In Japan, a country with a small land area, urban areas formed mainly on and around plains that stretch out along rivers have gradually sprawled into rural districts.

The improvement and widening of river channels in densely built-up urban areas require an enormous amount of cost and time. Broadening river channels does not always provide a reasonable solution to the issue of accommodating the peak flow of storm water resulting from the change in the storm water outflow mechanism brought about by rapid urbanization. Given this perspective, the most feasible and effective measure against flood disasters is to create a flood control reservoir that enables temporary retention of storm water in an area located in a middle or upper river region. However, it has become increasingly difficult to secure the land to build such a flood-control reservoir in an urban area. In this respect, the promotion of integrated urban development, which enables multiple land use, will cater to social needs, including the effective use of limited land.

Rural areas that have seen rapid urbanization have mixed characteristics of both urbanized areas, due to a highly developed network of roads and transportation systems linking them to a metropolis, and natural areas, featuring farmland and homestead woodland. Now that a demographical shift is expected from population increase to population decrease due to the aging population with fewer children being born, the focus of urban development has been placed on the creation of a more secure and mature community.

This paper introduces two integrated urban development projects in Japan, which set a significant precedent for such an attempt: the Tetsugakudo Park Collective Housing Development Project, which features three-dimensional and multiple land use to ensure both the supply of a safer and better housing environment and the provision of flood control functions, and the Koshigaya Lake Town Project, which has realized a more compact and attractive community with a flood control reservoir as a core of urban development, by taking advantage of the nearby greenery and rivers.

\section{Tetsugakudo Park Collective Housing Development Project}

\subsection{Project Background}

The Tetsugakudo Park Collective Housing is located on the

1) Leader, Urban Renaissance Agency (UR), Japan (Corresponding author: watanabe@ur-net.go.jp) 


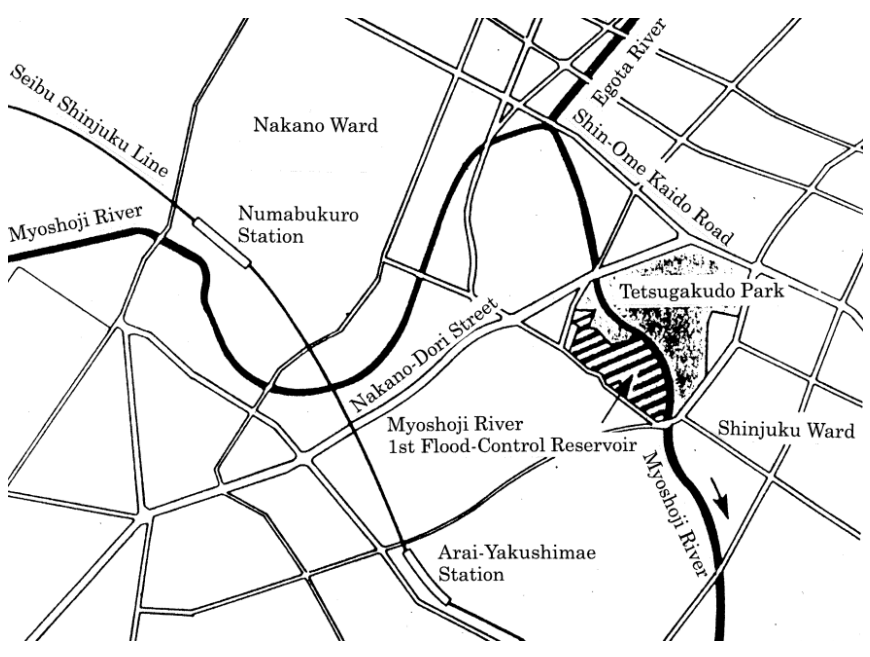

Fig. 1. Location Map

border between Shinjuku Ward and Nakano Ward in Tokyo, and is adjacent to the Myoshoji River, a tributary of the Kanda River. The Myoshoji River originating in Myoshoji Pond situated in Suginami Ward is a first-class river that runs eastward through the northern part of Nakano Ward and, after uniting at the lower part with the Egota River, flows into the Takadanobaba Diversion Channel of the Kanda River in Shimo-ochiai, Shinjuku Ward. This typical urban river is $9.7 \mathrm{~km}$ long and has a basin area of $21.4 \mathrm{~km}^{2}$, encompassing the crowded city blocks of the Suginami, Nakano and Shinjuku wards.

The old Myoshoji River was a meandering stream, whose basin area called Musashino used to have a wooded and farmland landscape. With the sprawl of urbanization, however, the area was inundated with flood waters whenever heavy rain fell. In 1975, river improvement work was conducted to accommodate rainfall of $30 \mathrm{~mm}$ per hour. In those days, the river administrator planned to further improve the river to cope with rainfall of 50 $\mathrm{mm}$ per hour, but the project made no progress because of concern that given a situation where the area at the junction of the Kanda River and the Myoshoji River was often subject to flooding, improvement of the river channel might increase flood disasters in the lower course of the river.

In general, when a river is improved by partially broadening its width, its effects are not as large as expected and, what is even worse, it might result in passing the problem on to the areas in the lower river. For this reason, it is much more effective to build a flood-control reservoir that can cut peak flow and mitigate flood damage at an early stage, rather than widening the cross-sectional area of the river. As part of its preventive efforts against overflow, the Tokyo metropolitan government decided to create flood control reservoirs that can accommodate rainfall of $50 \mathrm{~mm}$ per hour in an old factory site and public land along the Myoshoji River.

As for the move of a factory from the area concerned, a notification was submitted to the Tokyo metropolitan government in accordance with the National Land Use Planning Act. The land was most suited to the building of a flood-control reservoir. However, the land, situated between Shinjuku and Nakano wards in a central location of Tokyo, had too high a land value for the metropolitan government to carry out a project to create a flood-control reservoir single-handedly.

From the perspective of alleviating project cost burdens and promoting effective land use, the Tokyo metropolitan government called on Shinjuku and Nakano wards and the Housing and Urban Development Corporation (currently "Urban Renaissance Agency" (UR)) to participate in a joint project to promote multipurpose utilization of the land.

\subsection{Project Outline}

The interests of the Tokyo metropolitan government and the other three parties coincided with one another: Shinjuku and Nakano wards hoped to create a park for local citizens, and the UR desired to build a housing development that offered greater convenience to residents. In March 1984, the project began with the construction of a flood-control reservoir, which was followed by a housing complex and a park. For the project outline, please see Table 1.

As shown in Table 2, which shows the land use, the land cost burden ratio and the land ownership ratio, the project cost was significantly reduced compared to that necessary for individual projects independently implemented by individual developers. This joint project enabled the Tokyo metropolitan government to use the entire area of the project as a river zone by bearing $42 \%$ of

Table 1. Project Outline

\begin{tabular}{c|c|c|c}
\hline \multirow{2}{*}{ Total Site Area } & \multicolumn{3}{c}{$11,463 \mathrm{~m}^{2}$} \\
\hline \multirow{2}{*}{ Project Master Plan } & Facility & Spec. & Project Developer \\
\cline { 2 - 4 } & Flood-control reservoir & $30,000 \mathrm{~m}^{3}$ & Tokyo metropolitan government \\
\cline { 2 - 4 } & Park & $7,600 \mathrm{~m}^{2}$ & Shinjuku and Nakano wards \\
\cline { 2 - 4 } & Collective housing & UR units \\
\hline Total Project Cost & \multicolumn{3}{|c}{ Dec. 1981 - March 1987 } \\
\hline Project Period & \multicolumn{3}{|c}{ March 1984- March 1987 } \\
\hline Construction Period & \multicolumn{3}{c}{} \\
\hline
\end{tabular}


the total land cost, and the UR to acquire $50 \%$ of land ownership by bearing $25 \%$ of the land cost. Moreover, all the area covered by the project was allowed to be used as a site area under the Building Standards Act.

To designate the entire site area as a river area, an administration agreement was concluded between Shinjuku Ward, Nakano Ward, and the UR. An agreement concerning administrative burdens was also signed by the Tokyo metropolitan government, Shinjuku Ward and Nakano Ward to ensure the proper functions of a flood-control reservoir and a park, eliminating the need to establish an easement or to pay for occupancy of the river zone.

\subsection{Facility Outline}

As for the land use of the project area, the Tokyo metropolitan government, in charge of river management, used almost the entire area as a flood-control reservoir; Shinjuku and Nakano wards, responsible for park management, used approximately two thirds of the area as a park, and the UR used the other one third as a site for a high-rise housing complex.

\subsection{Flood-Control Reservoir}

In the case where the water level of the Myoshoji River surges due to heavy rain, river water flows into the intermediate flood-

Table 2. Land Cost Burden, Land Use and Ownership

\begin{tabular}{c|c|c|c}
\hline & Land Cost Burden & Land Use & Ownership \\
\hline River (Tokyo metropolitan government) & $42 \%$ & All the site (river zone) & - \\
\hline Park (Shinjuku and Nakano wards) & $33 \%$ & $66 \%$ & $50 \%$ \\
\hline Collective Housing (UR) & $25 \%$ & All the site in volumetric terms & $50 \%$ \\
\hline
\end{tabular}
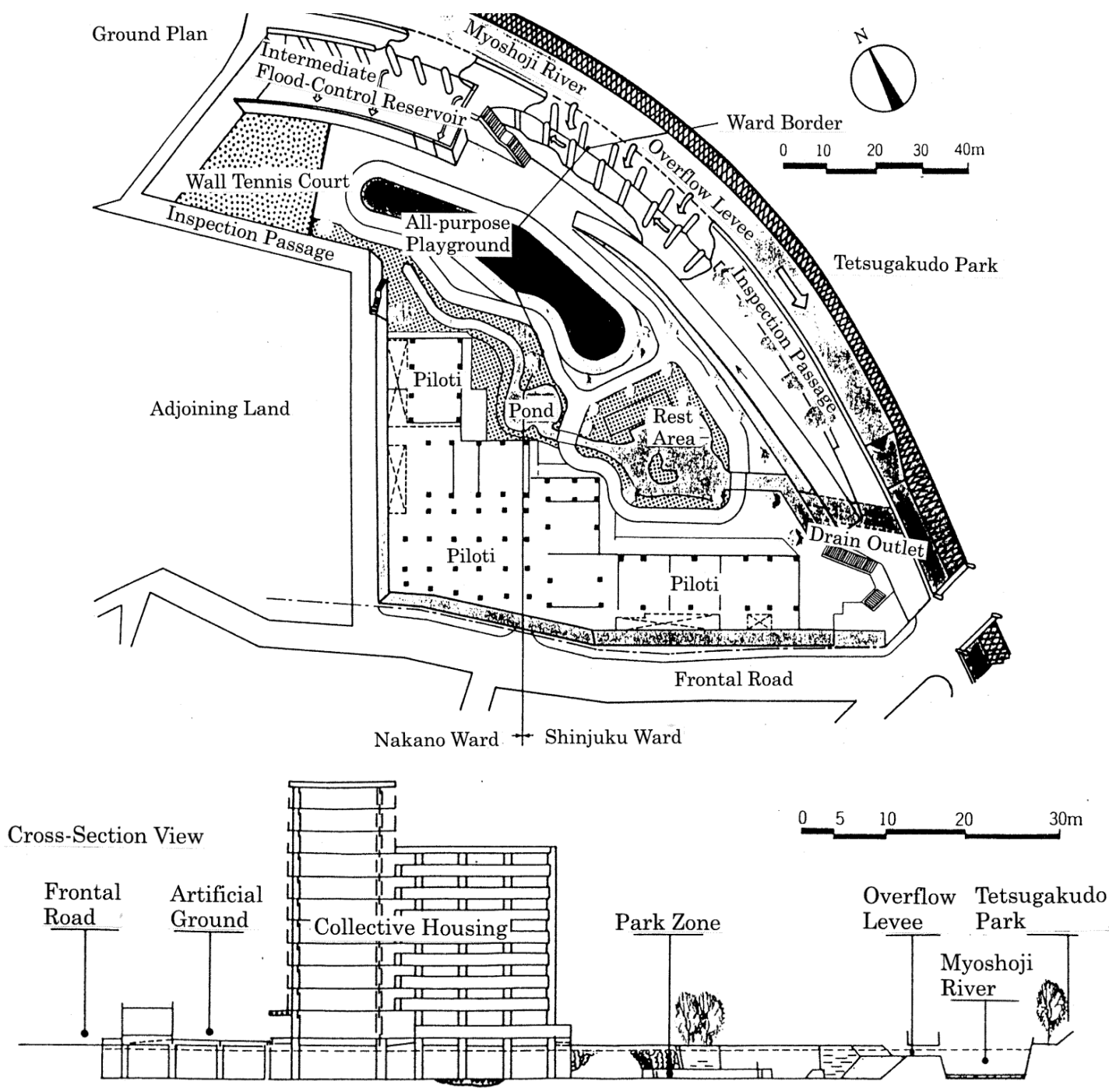

Fig. 2. Myoshoji River 1st Flood-Control Reservoir 


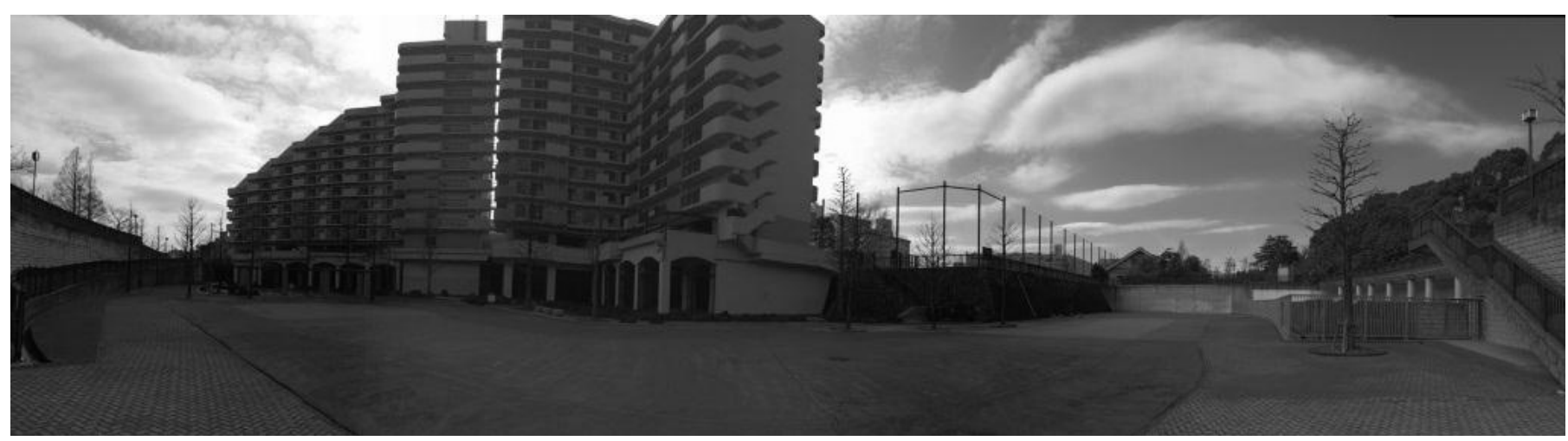

Photo 1. Tetsugakudo Park Collective Housing and Flood-Control Reservoir

control reservoir via an overflow levee constructed in the river revetment. Once the reservoir is filled with water, the park zone and the piloti of the apartment buildings serve as another reservoir. This two-stage storm water retention system is characterized by the natural inflow and outflow of water through a drainage channel of the downstream reservoir as the river water level is lowered. This reservoir system can retain up to $30,000 \mathrm{~m}^{3}$.

The inflow of water into the park zone, which begins when rainfall exceeds $30 \mathrm{~mm}$ per hour, is expected to take place once or twice a year. It is estimated to take about one hour to fill the park zone with storm water, depending on rainfall patterns. The data recorded after the reservoir system went into operation also show that water inflow into the park zone occurs at a frequency of twice a year in general, with a maximum water depth of $230 \mathrm{~cm}$ (As of 1995).

The two-stage reservoir system adopted for this project has four major characteristics.

(1) The overflow section and the section of water inflow into the reservoir are movable.

(2) Intermediate water storage serves as an energy absorber for the inflow of water into the reservoir.

(3) The one-time storage capacity of the intermediate floodcontrol reservoir is approximately $2,500 \mathrm{~m}^{3}$; if the influx of water does not exceed its capacity, the reservoir can prevent the inflow of water into the park area and decrease the frequency of cleanup activities in the park.

(4) Time for evacuation can be secured by storing storm water in the intermediate flood-control reservoir.

\subsection{Park Zone}

As shown in Fig. 2, the park zone consists of an all-purpose playground including a roller-skating rink and a wall tennis court, and a recreation area with a pond, plants and trees, and a pergola. These facilities are open to the public, and in the recreation area, children playing in the water are a familiar scene, creating a comfortable water-friendly living environment.

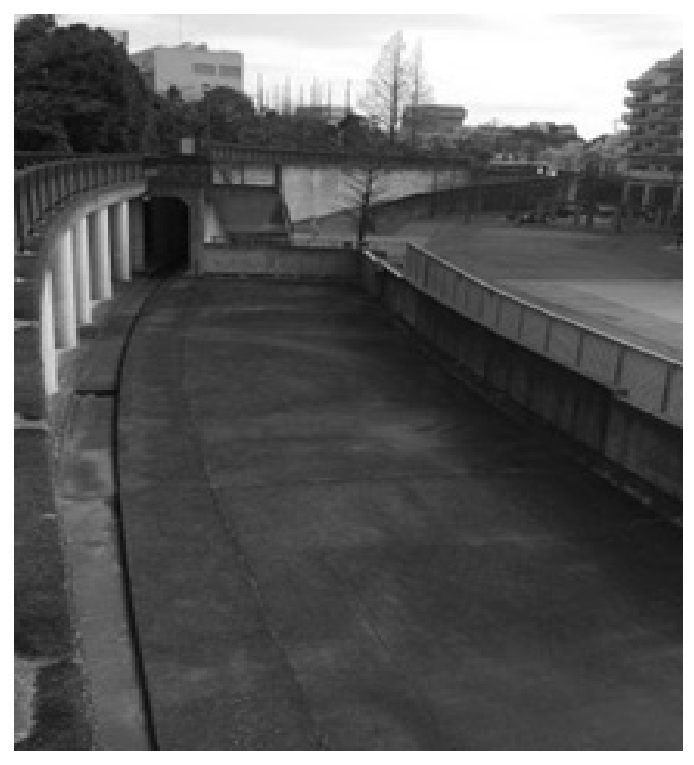

Photo 2. Intermediate Flood-Control Reservoir

Typical Cross-Section

- Open Inlet (Overflow Levee)

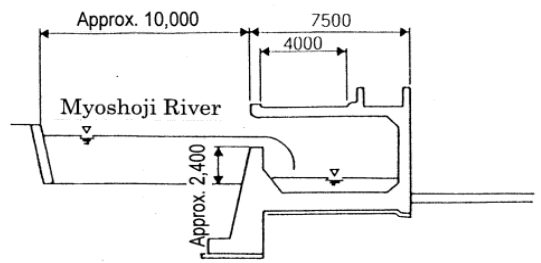

- Open Inlet (Intermediate Flood-Control Reservoir)

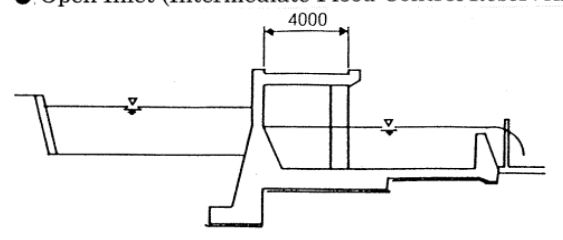

- Drain Outlet (at the time of drainage)

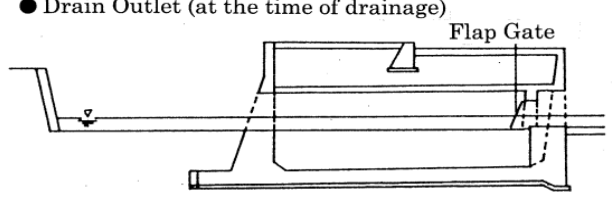

Fig. 3. Typical Cross-Section View 


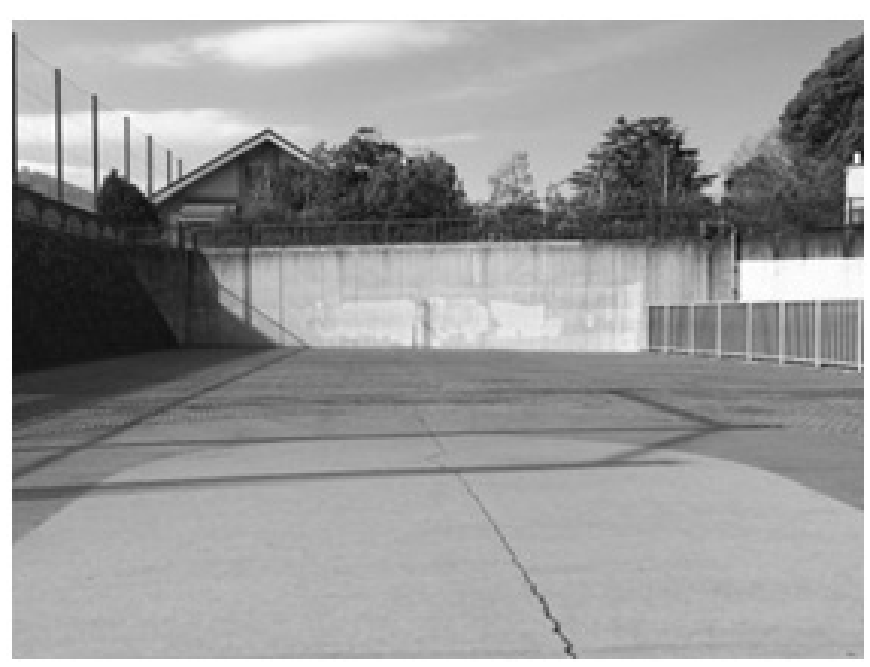

Photo 3. All-purpose Playground

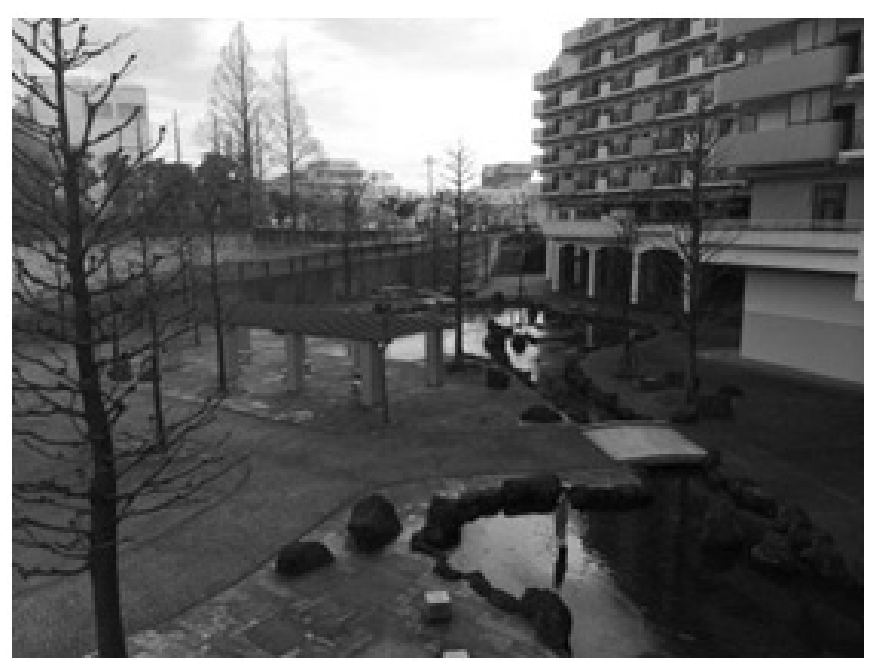

Photo 4. Rest Area

\subsection{Collective Housing}

For the construction of an apartment building, there were two requirements to be met.

(1) Keep the number of pillars and walls to a minimum on the ground floor of the apartment building, which acts as a flood-control reservoir.

(2) Construct an apartment building in the southwest part of the site to ensure a larger park zone.

The first requirement was satisfied by employing a piloti style (an elevated-floor style using special beams) and creating an artificial ground for common use space and other facilities, raising construction costs higher than normal.

The second requirement was fulfilled by applying the integrated architectural system based on the Building Standards Act to ease setback regulations regarding road width and adjacent land, and

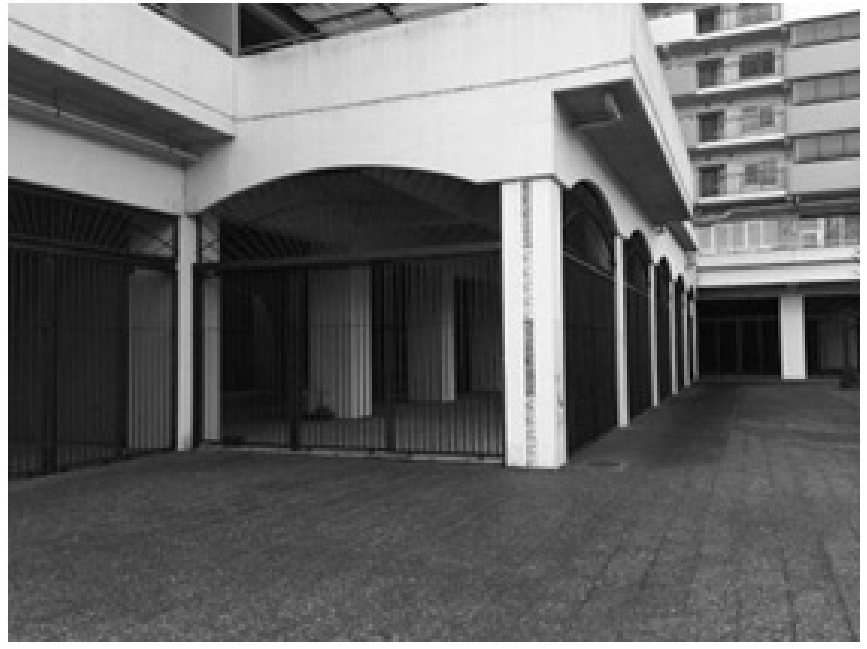

Photo 5. Piloti of Collective Housing

by changing the height of part of the building from five stories to 11 stories.

The building is a 16-minute walk from the nearest train station (Seibu-Shinjuku Station). However, considering that it is located in a favorable dwelling environment, such as being adjacent to Tetsugakudo Park, most housing units of the apartment building are 3DK (three rooms plus a dining room-kitchen) designed for families, attracting about 18 times as many applications for rental as there are housing units available (in 1986).

\subsection{Facility Maintenance and Management}

To clarify maintenance and management responsibility in the shared areas, an administration agreement was concluded between Shinjuku Ward, Nakano Ward, and the UR. An agreement concerning administrative burdens was also signed by the Tokyo metropolitan government, Shinjuku Ward and Nakano Ward.

Under the agreement concluded between the UR, Shinjuku Ward and Nakano Ward concerning the maintenance and management of facilities on the multipurpose flood-control reservoir site, the UR is responsible for the maintenance and management of the fence installed on and in front of the piloti of the apartment building in normal circumstances, and if flooding occurs, the two wards must perform the following four tasks.

(1) To remove all debris and clean up (wash with water) the open ground floor of the apartment building, including walls and pillars.

(2) To clean U-shaped gutters on the open ground floor of the apartment building, including the removal of mud.

(3) To clear off the fence, including the removal of paper and wood debris.

(4) To disinfect the fence and the ground floor of the building. 


\subsection{Safety Measures against Flooding}

In the case of flooding, Shinjuku and Nakano wards activate facility alarms and take necessary evacuation measures with the cooperation of the UR, in accordance with the provisions of the aforementioned agreement. Specifically, a stationed facility keeper sounds sirens and issues voice warning message in two stages.

(1) The 1st stage: When the water level of the river rises to 50 $\mathrm{cm}$ below the overflow levee crown, a three-minute siren is sounded, together with a two-cycle voice warning message saying "The water level of the river is rising quickly. Please leave the park immediately."

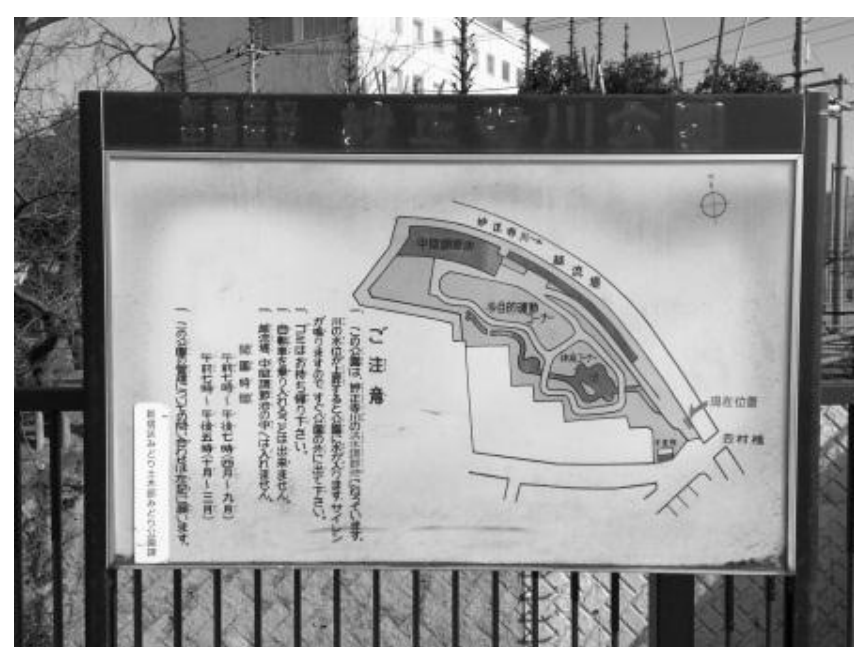

Photo 6. Signboard for Flood-Control Reservoir

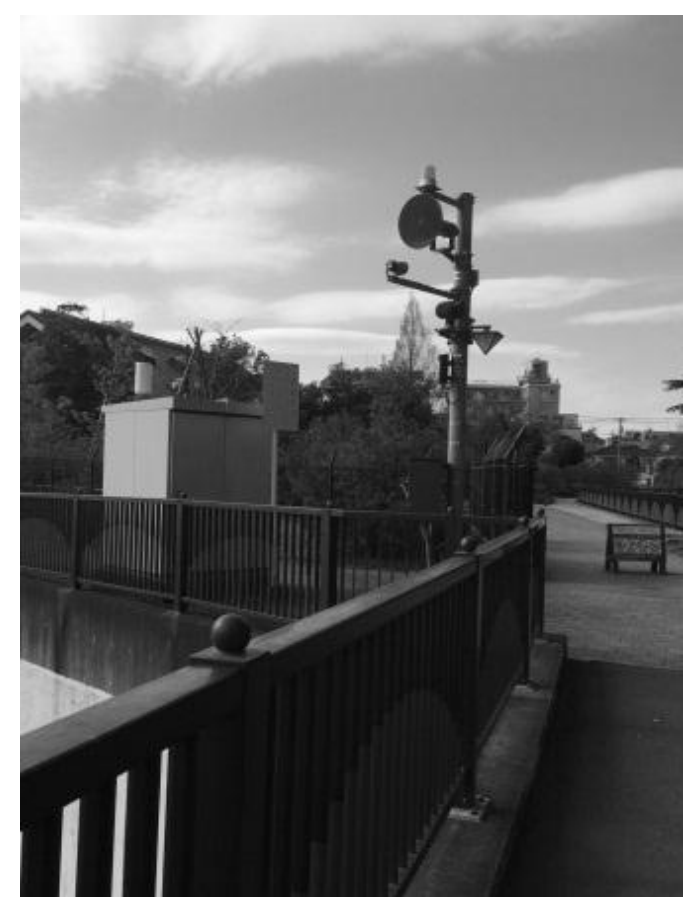

Photo 7. Alarming Device
(2) The 2nd stage: When the water levels rise to $50 \mathrm{~cm}$ below the weir crest of the immediate flood-control reservoir, a two-minute siren is sounded, together with a two-cycle voice warning message saying "The park is being flooded with water. Please leave here immediately."

In addition to these measures, public relations activities have been conducted to raise facility users' awareness of disaster prevention measures.

\subsection{Evaluations by Residents}

This is Japan's first attempt to construct an apartment building on flood-control reservoir premises, as a result of a three-dimensional integrated development of a river, a park and collective housing. The apartment building was opened in September 1986. For future reference, the UR conducted a questionnaire survey of the residents of the apartment building in 1989.

\subsection{Survey Outline}

A questionnaire survey was carried out of 163 households (all the housing units) living in the apartment building. Completed questionnaires were collected from 125 households (a collection rate of $77 \%$ ) by making visits to each household. Many of the respondents were aged from 30 to 40 years. Approximately $90 \%$ of all the respondents were men. The most common occupations were company workers and civil servants.

Major questionnaire items are:

(1) The use and evaluation of the park

(2) Residents' awareness of the flood-control reservoir

(3) Residents' awareness of the submergence of the flood-control reservoir

(4) Overall evaluation of the park and the housing building constructed taking advantage of the flood-control reservoir

\subsection{Survey Results}

(1) Questioned about their use of the park, $24 \%$ of respondents answered that they use it "several times a year," which was followed by "once a month or so" and "a couple of times a month." The facility that received the highest evaluation was the pond and water area, with about $60 \%$ answering "satisfied" or "somewhat satisfied." The rest area was the facility that gained the second highest evaluation. Among children, most popular was the roller skating rink, with $70 \%$ answering "satisfied," which was followed by the pond and water area.

(2) Asked about how they learned that the park serves as a flood-control reservoir, some $80 \%$ of the respondents cited a "pamphlet for applications for rent" or an "explanatory meeting for residents," indicating that they knew it before their occupancy. Approximately $25 \%$ of respondents gave consideration to the 
function of the park as a flood-control reservoir when deciding to live there.

(3) Regarding the sirens and voice warning messages sounded when the reservoir is flooded, about $25 \%$ of the respondents, excluding those who were away from home at the time, answered that it "could not be heard clearly or could not be heard at all." Moreover, about $60 \%$ said that they knew about the sirens and voice warning messages through a notice posted on a park bulletin board, and $15 \%$ answered that they learned about them through this questionnaire. These answers indicate that this is a crucial issue to be addressed.

Asked about their experience with flooding, about $60 \%$ answered that they "Learned what functions the flood-control reservoir plays," and $65 \%$ said they were "Worried about its damage to the park and building." With regard to their evaluation after flooding, some $80 \%$ answered, "Same as before" or that they were "Relieved to learn that the facilities were cleaned and disinfected."

(4) Concerning the overall evaluation, more than $80 \%$ said "Satisfied" or "Somewhat satisfied." About 70\% said they were "Satisfied" or "Somewhat satisfied" with the park that serves as a flood-control reservoir, which received a high evaluation among the residents.

\subsection{Project Effectiveness}

The major effectiveness of this project - Japan's first attempt to realize a three-dimensional integrated development of a flood control reservoir, a park and collective housing - can be summarized into four points.

(1) The costs borne by individual project developers were significantly reduced by realizing a high degree of application and multipurpose use of the land through a joint project.

(2) This project, which was designed to accommodate rainfall of 30 to $40 \mathrm{~mm}$ per hour, is expected to contribute to reducing flood damage and generating significant investment effects, in terms of asset value in downstream areas, thereby increasing flood control security.

(3) Local disaster prevention functions were enhanced by providing an evacuation site in the case of an earthquake.

(4) The living environment was improved by adding the function of a park.

In this project, the UR was responsible for housing construction and housing maintenance and management, which ensured the functions of a flood-control reservoir and a park. This threedimensional and integrated river facility development, which met the interests of all the project implementing bodies, is expected to generate significant effects in terms of flood control in urban areas and effective land use.

The River Act was revised in 1995 to establish a three- dimensional river area system, which enables the three-dimensional use of rivers and other facilities, and since then the system has been applied to many areas in Japan.

\section{Koshigaya Lake Town Project}

\subsection{Project Background}

Koshigaya Lake Town is in Koshigaya, a city situated within a $25 \mathrm{~km}$ commuting distance from central Tokyo. The city, like the suburbs of the other three major metropolitan areas, features mixed characteristics of both urbanized areas and rural areas.

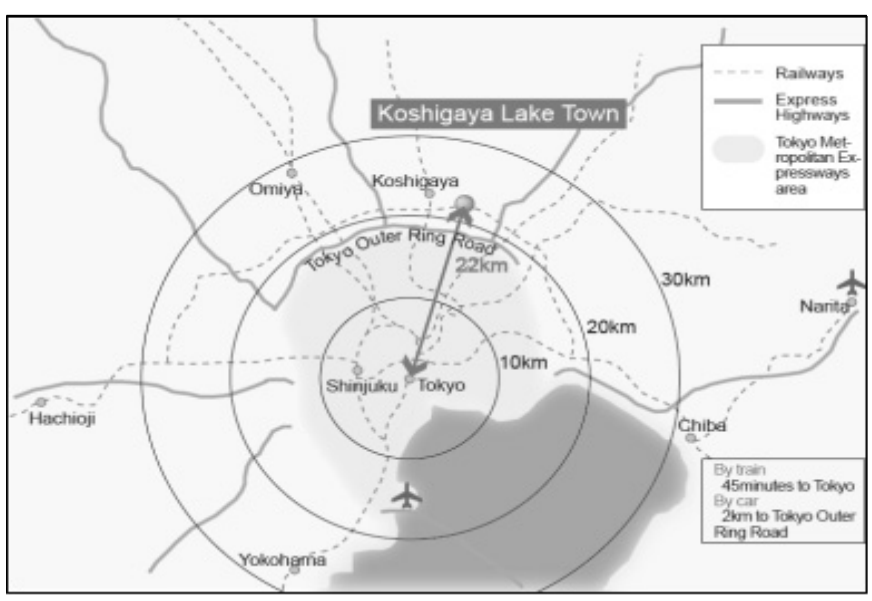

Fig. 4. Location Map

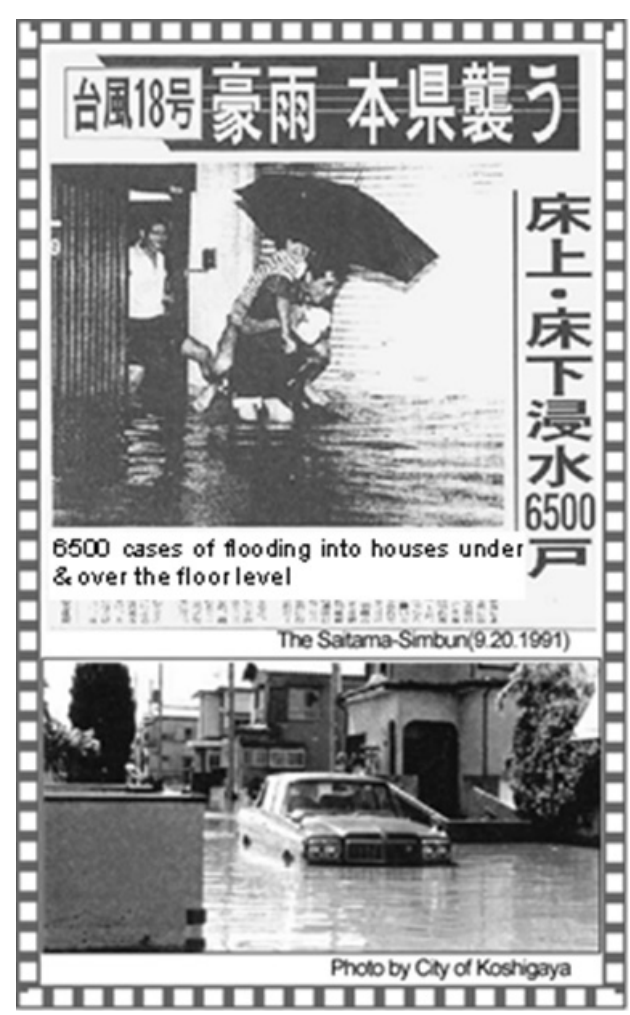

Photo 8. Newspaper Reporting Flooding Disasters 
The entire region around the City of Koshigaya, in which a lake town was constructed under this project, was geographically a wetland fed by the overflowing Moto-Arakawa River, Nakagawa River and other nearby rivers, forming a rural area with stretches of rice fields. With rapid urbanization, however, this area saw suburban sprawl. As a result of land use conversion into urbanized areas, the capacity for ground-water retention diminished considerably compared to when water-holding rice fields existed, thereby causing an increased outflow of storm water onto the ground surface. Moreover, this area, surrounded by rivers and situated only about 3 to 7 meters above sea level, was often plagued with flooding from heavy rainfall, especially during typhoons.

The central government attempted to mitigate flooding disasters by taking various measures such as improving riverbanks and installing drainage pump facilities. However, because of the rapid urbanization all along the rivers, a larger scale solution for flood control encompassing the whole region-wide river basin was deemed to be necessary.

To respond to these situations, a committee, consisting of expert scholars, the central government, Saitama Prefecture, Koshigaya City and the UR, was launched in 1986 to create a model city with a flood-control reservoir as the core of urban infrastructure and offering both waterfront amenities and an urban living environment. After much consultation with the other committee members, the UR was fully committed to procuring the land for a flood control reservoir, the key to the project, by promoting river development projects and land readjustment projects.

Conventional land readjustment methods for procurement of the land for a flood-control reservoir often impose a substantial burden upon landowners, who need to contribute their land for public facilities, making it difficult to obtain landowners' agreement and increasing developers' financial burdens. To resolve this issue, the Koshigaya Lake Town Project adopted the "land replotting and land contribution method" to procure the land necessary for a flood-control reservoir. The river developer bore the cost of the land necessary for its development in the form of public facility administrator's contributions. This method made it possible to conduct an unprecedented new form of urban development: a large-scale flood-control reservoir development project and a land readjustment project were implemented in an integrated way.

\subsection{Project Outline}

The project outline is shown in Table 3. The key components of the Lake Town Project are:

(1) A large artificial flood-control reservoir

(2) An open space of water and greenery

(3) Trunk roads to channel wind flow

(4) Protection from flooding

(5) A recreational function for healthy lifestyles

\subsection{Major Features of the Lake Town Project}

The remarkable feature of this Project in terms of land use and urban infrastructure is the introduction of a large expanse of water, totaling 39.5 hectares, which is open to the public as a public waterside park. The flood-control reservoir, or "Lake," protects the community from flooding disasters and also functions as a cooling spot for the surrounding areas during hot weather. Other key environmental functions provided by the Project are the vista corridor extending from the railway station plaza to the Lake and the axes of trunk roads to channel the wind flow from the cool spot. To take full advantage of the wind flow, special consideration was paid to the designs of houses, such as the locations of hedges and trees around the houses and the orientation of windows to reduce the environmental burden of air conditioning.

By locating the commercial complex and the residential zone within a $1 \mathrm{~km}$ radius from the railway station, the open spaces in the center of town are enjoyed by residents and visitors alike, symbolizing the harmonious coexistence of nature and people and contributing the formation of a community compatible with the natural environment. This lake town is designed to promote the use of buses and bicycles, and walking, instead of using personal cars as the basic means of transport, in order to realize a low-carbon community. This project is also aimed at creating a compact mixed-use complex that accommodates the activities of living, shopping, entertainment, learning and working. This is an

Table 3. Project Outline

\begin{tabular}{l|l}
\hline Development Classification & Koshigaya Laketown Land Readjustment Project \\
\hline Project Developer & The Urban Renaissance Agency (UR) \\
\hline Development Site Area & 225.6 ha Total (of which the Reservoir comprises 39.5ha) \\
\hline Planned Population & Approx. 22,400 people (about 7000 families) \\
\hline Project Period & $1999-2013$ (excluding project close-out) \\
\hline Number of Landowners & Approx. 800 \\
\hline $\begin{array}{l}\text { Contribution Ratio } \\
\text { (as compensation for resulting land appreciation) }\end{array}$ & $\begin{array}{l}40.6 \% \text { Overall contribution ratio } \\
\text { Contribution ratio breakdown: } 24.3 \% \text { for infrastructure usage \& } 16.3 \% \text { for reserved land) }\end{array}$ \\
\hline Total Project Budget & Approx. JPY 89.7 billion \\
\hline
\end{tabular}




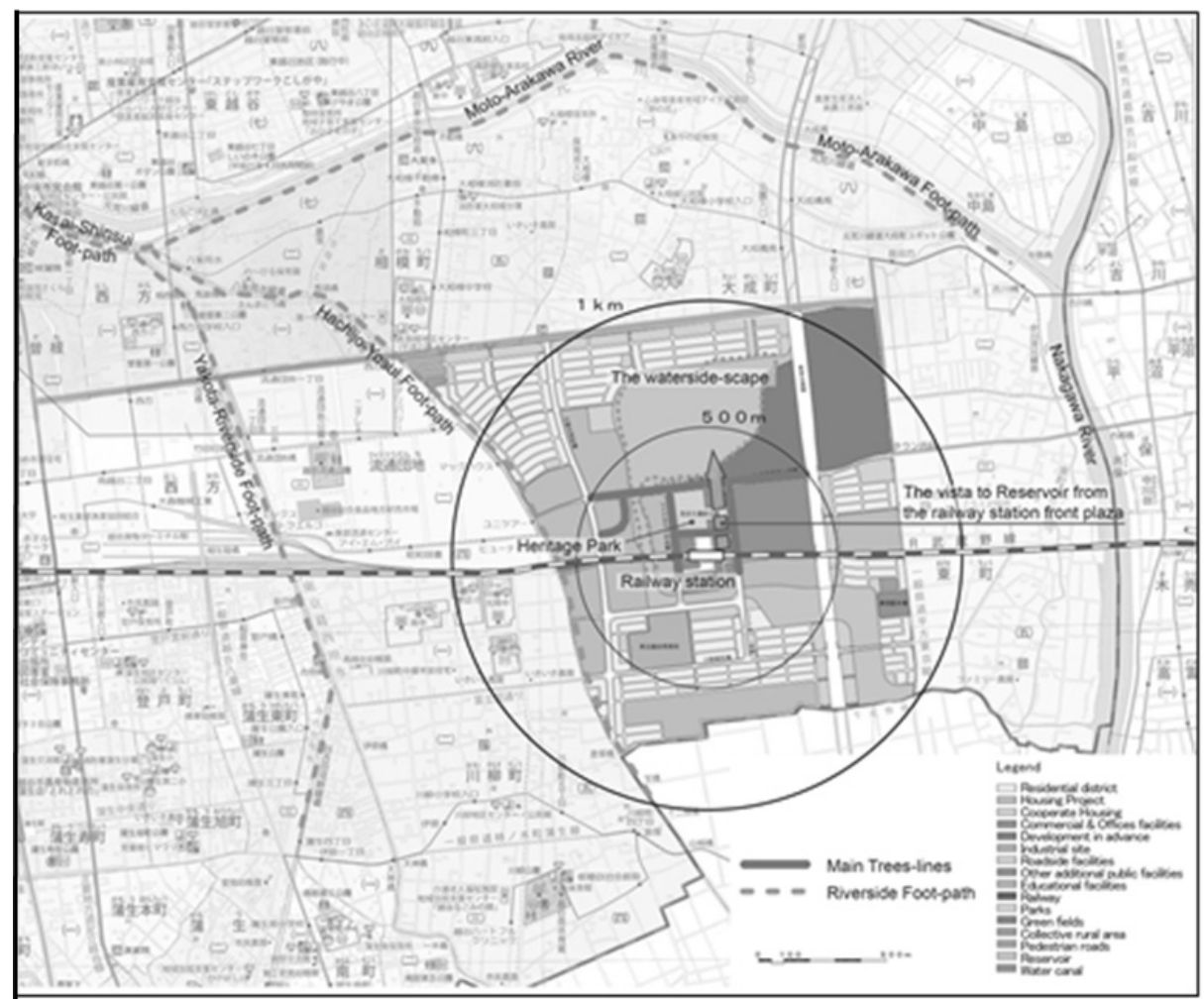

Fig. 5. The Land-use Plan of Koshigaya Lake Town and the Surrounding Areas

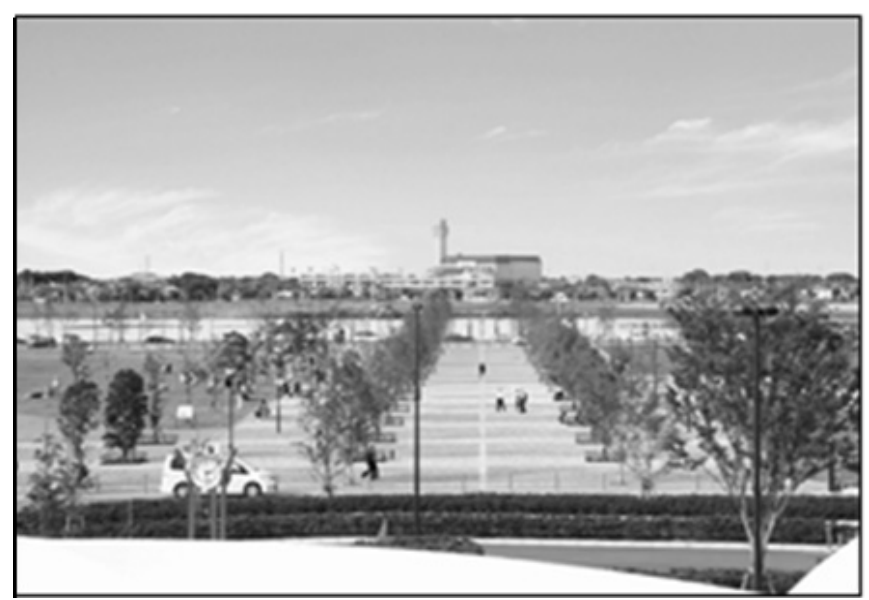

Photo 9. The Vista to the Lake (reservoir)

example of the creation of a community responding to a society that is aging at a speed unparalleled elsewhere in the world and offering a residential environment and urban systems that are safe, secure and sustainable into the future.

Other notable urban design features are a flat expanse of land from the railway station plaza to the park and the Lake, and a pleasant vista of the promenade lined with a unique variety of local trees, which has an optical effect leading pedestrians to the waterfront. Moreover, the trees planted in the project area create a green network, contributing to the formation of a regional green environment.

\subsection{The Lake: Flood-Control Function and Effectiveness}

As a countermeasure against flooding for the entire region, including the project area, a vast lake with an area of 39.5 hectares was created. When the water levels of the MotoArakawa River surge due to heavy rain, the Lake acts as a flood-control reservoir, allowing the flow of river water into the Lake via a culvert. It can hold rain water up to a depth of 5 meters, equivalent to 1.2 million $\mathrm{m}^{3}$ of controlled water. After the heavy rain subsides and the water levels of the Nakagawa River located downstream southeast of the Project area drop, the reserved water is drained through a culvert into the river. The flood-regulating mechanism of the Lake mitigates the danger from urban disaster of the entire water basin and serves to substantially elevate the sense of safety and security of the residents, thereby contributing to the social benefit of the whole region.

Normally the water of the Lake is circulated by the flow caused by the varying water levels (tidal energy), through which water quality is ensured. The "Lake-side Walk" that runs along the edge of the water is enjoyed by local residents as a place for recreational activities, including jogging and bicycling. A pier and a floating stage are also used as a place to enjoy canoeing and sailing. Some parts of the tranquil shore protected by ecological blocks make the waterfront viable as a biotope environment where aquatic creatures and plants, including an indigenous species of ancient lotus plant, can live and flourish. This biotope area has been developing as an environmental education field.

The UR, recognizing that the local community plays an 


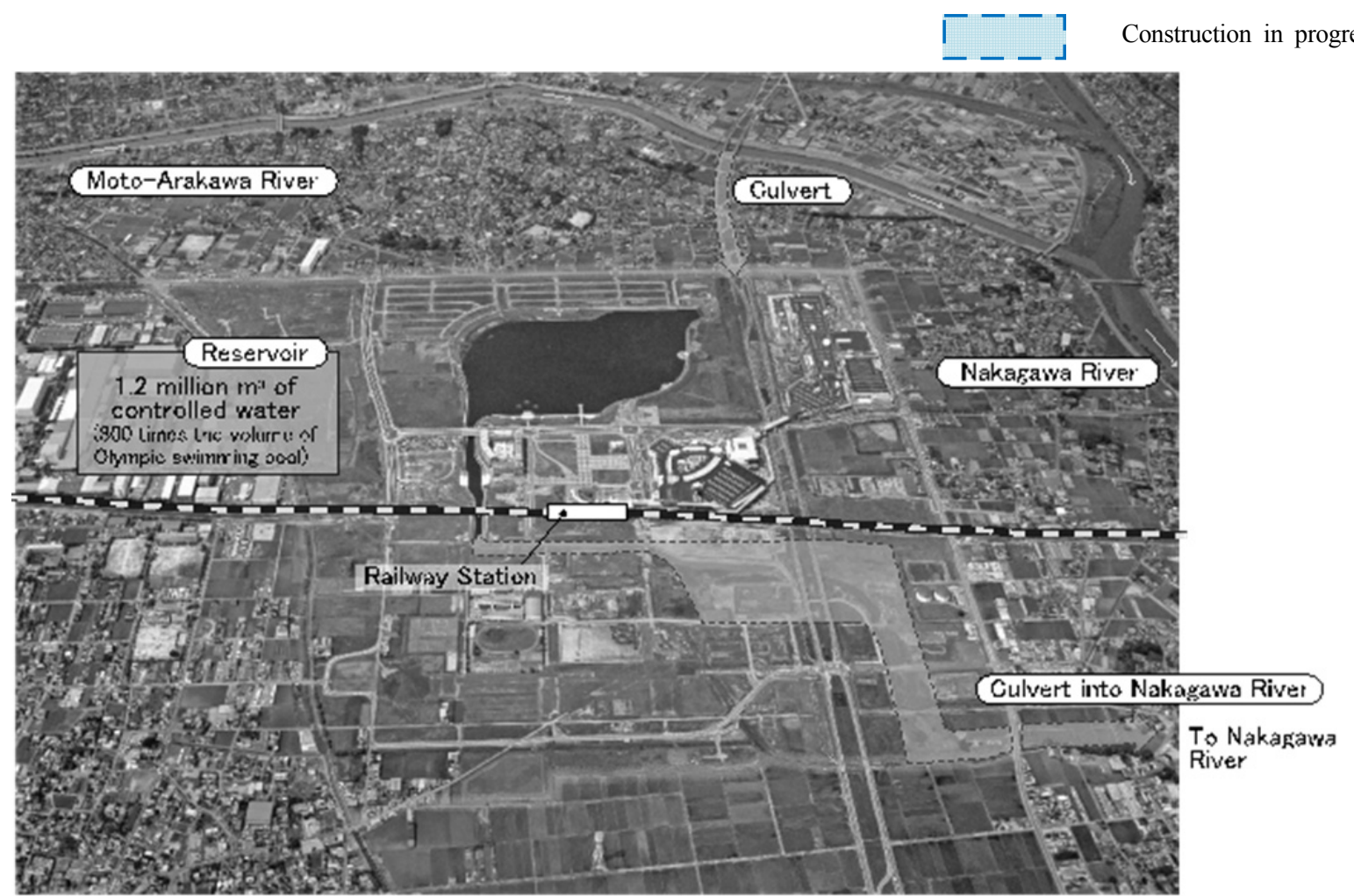

During high water level in the river caused by heaw rainfall

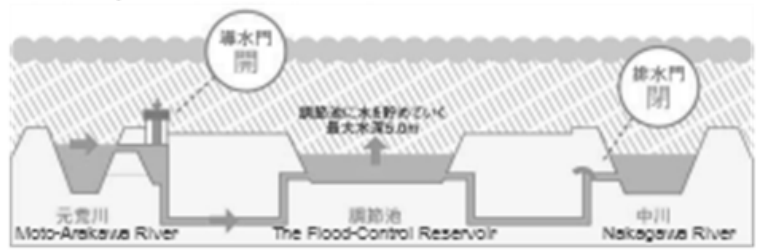

During low water level in the river

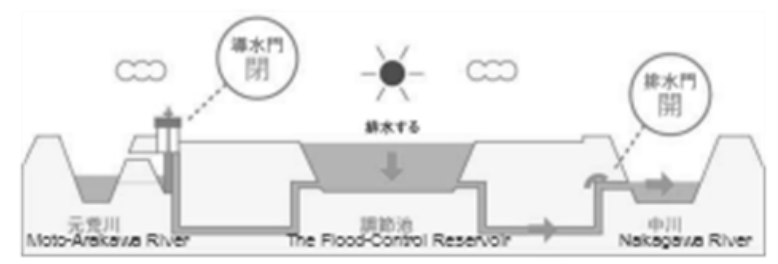

Photo 10. The Flood-Control Reservoir (the Lake)

important role in the maintenance and management of the Lake, called on citizens to form an organization to consider the Lake's utilization in cooperation with Saitama Prefecture and Koshigaya City. Firstly, efforts were made to enhance public understanding of the functions played by the Lake in disaster prevention, nature protection and recreational activities, and to form a public consensus on its utilization and management. In the second year and afterward, the focus of the organization's activities was placed on the following three topics. These activities have also contributed to enhancing citizens' awareness of the importance of maintaining and managing the Lake.

Topic 1: To revive the rural landscape as a "City of Water" in natural areas around the biotope where the waterside environment and human activities coexist in harmony.

Topic 2: To create places where citizens engage in spontaneous and recreational activities, such as cultivating flower beds, around the Waterside Park.

Topic 3: To develop the waterside zone in the central area, which provides easy access from the station and the park, as a base for water sports activities.

After consideration of their feasibilities, these proposals were reflected in the present landscape design and waterside facilities.

The rapport established among the citizens through participation in the discussion groups leads to a greater sense of the identity of the community they are living in. As a result, the "Koshigaya Laketown Hometown Project" was launched in June 2007, as a voluntary organization to maintain and manage the Lake Town. Its activities include the monitoring and protection of the natural landscape of the lakeside and the promotion of recreational activities among citizens.

As stated above, former and new residents have been enjoying a wholesome, water-friendly life in the community developed with the Lake as its core environmental system, providing them with an opportunity to take a look at global environmental issues and forming a new more environmentally friendly lifestyle. The sense of community that supports the creation of a water-friendly culture has now begun to emerge. 


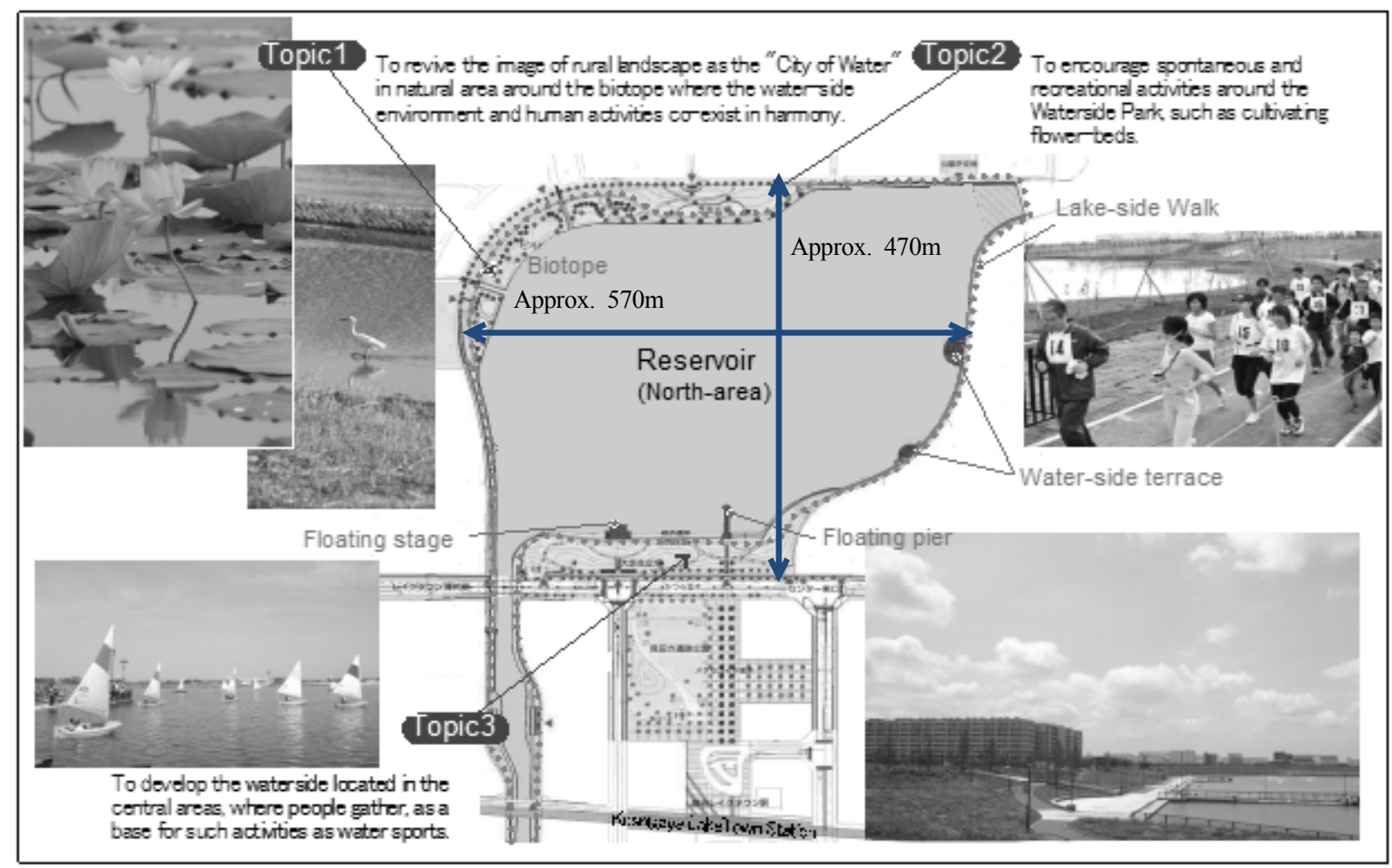

Photo 11. Utilisation of the Flood-control Reservoir (the Lake)

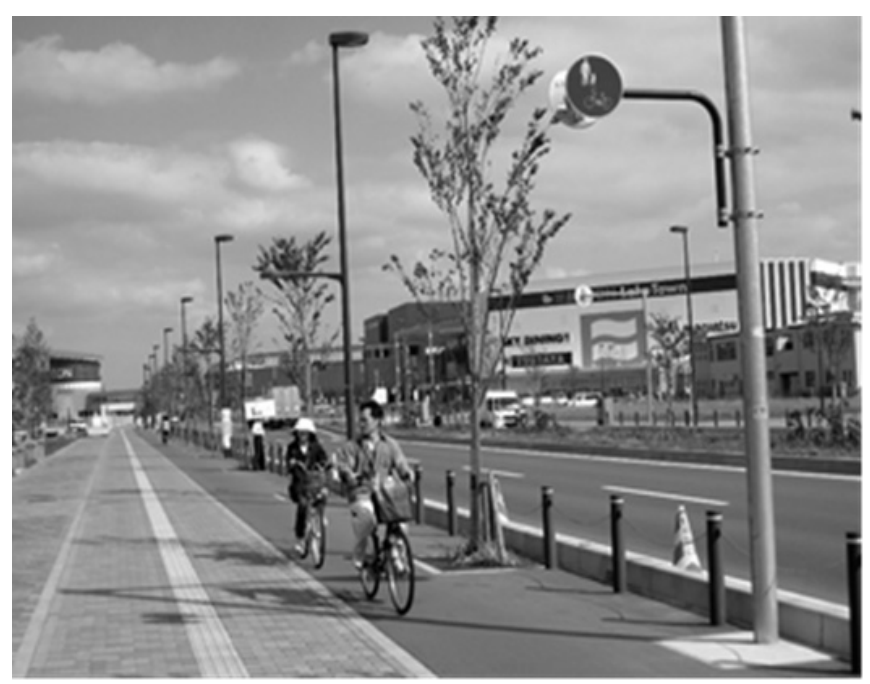

Photo 12. Bycycle Lanes along Trunk Roads Paved with Re-cycled Slag Paving Blocks

\subsection{Coordination with Private Enterprises in Creating a Community Conducive to Coexistence with the Environment}

In the development of urban infrastructure, the UR has promoted the effective utilization of resources. For example, blocks made from recycled slag collected from waste incinerators are used to pave plazas and walkways. Water-retentive pavement in particular can reduce the surface temperature by 10 to 20 degrees compared to ordinary paving blocks during the summer, because of its evaporating qualities, a study reveals. The water conserved in the Lake not only serves to mitigate the heat island effect, but has also made it possible to generate a viable biotope for aquatic organisms in an urban setting.

As part of efforts to realize a low-carbon society, a network of pedestrian and bicycle paths to link the amenities around the Lake, including the residential areas and the town center, has allowed citizens to use public transportation services or bicycles, or to walk for transport and minimize their dependency on cars.

Another notable aspect in the land-use planning was that the UR designated an area adjacent to the Lake as a model of an environmentally friendly area to pursue the realization of a community that allows the harmonious coexistence of people and nature, a key concept of the Koshigaya Lake Town Project.

For this model area, the UR set guidelines and criteria concerning the offer of land to private enterprises for development in order to promote the construction of residential houses that meet nextgeneration energy saving standards as well as the utilization of energy with the least adverse impact on the environment. Under these guidelines, real-estate developers are required to reduce $\mathrm{CO}_{2}$ emissions by more than $20 \%$. When inviting private enterprises for this project, the UR examined their construction plans and business proposals to ensure their conformity with the project guidelines.

The UR took the initiative in selecting enterprises for the project and the coordination of the town development. Moreover, 


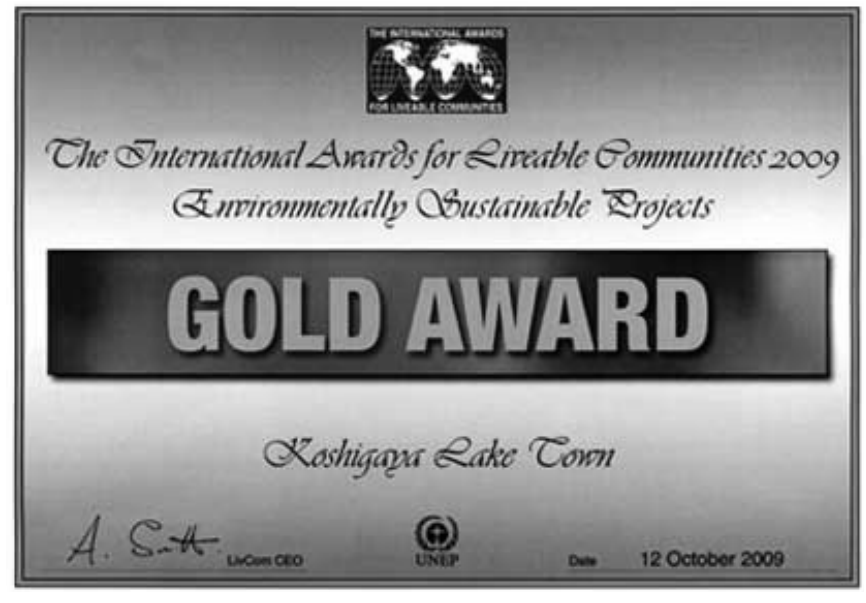

Photo 13. Gold Award of The LivCom Awards 2009

the UR worked together with participating housing developers to promote energy conservation, including the use of solar energy.

\subsection{Results of the Koshigaya Lake Town Project}

The Koshigaya Lake Town Project won the Gold Award in the Environmentally Sustainable Project category at the 2009 International Awards for Liveable Communities (The LivCom Awards), in recognition of its efforts toward harmonious coexistence with nature.

The Project is scheduled to be completed in 2013. After that, the responsibility of community development will be handed down from the developers to the local residents. Koshigaya Lake
Town aims to be an affluent community where individual citizens can enjoy a healthy, water-friendly lifestyle, be aware of global environmental issues, and take specific action toward the realization of a low-carbon society.

\section{Conclusion}

The UR has worked together with local governments to promote large-scale urban development and housing development. The two projects introduced in this paper are the results of the UR's years of efforts toward integrated development, taking advantage of a flood-control reservoir.

With the aim of securing local flood control, the UR has currently been working on the active utilization of technology to prevent the outflow of rain water to outside a specific area by retaining or infiltrating rain water on site (The technology has been adapted so far for the construction of 370 units of housing complexes).

\section{References}

1. Shimada, Hiroyasu (1995), "First Flood-Control Reservoir in the Myoshoji River: Integrated Project of a river, a park and housing", Civil Engineering, 50(12): 59-65.

2. Urban Renaissance Agency (2009), Koshigaya Lake Town Project (submitted for interim screening for the International Awards for Liveable Communities 2009, Environmentally Sustainable Project Awards). 